\title{
Nanosilver Immobilized in Carbonaceous Particles Derived from Hydrothermal Carbonization of Eleusine indica Leaf Extract
}

\author{
Marilyn Lalunio-Manikan ${ }^{1,2}$, Aldrin P. Bonto ${ }^{3,4, *}$ and Carmelo Miguel H. Ebreo ${ }^{3,5}$ \\ ${ }^{I}$ Department of Graduate Studies, De La Salle University, Dasmariñas, DBB-B, West Avenue, \\ Dasmariñas, Cavite 4115, Philippines \\ ${ }^{2}$ Casa de San Miguel Montessori School, Bacoor, Cavite 4102, Philippines \\ ${ }^{3}$ Department of Chemistry, De La Salle University, Manila, 0922, Philippines \\ ${ }^{4}$ Department of Chemistry, College of Science, University of Santo Tomas, Manila 1015, Philippines \\ ${ }^{5}$ Department of Physical Science, Pamantasan ng Lungsod ng Maynila, General Luna, \\ Manila 1002, Philippines
}

('Corresponding author's e-mail: aldrin.bonto@dlsu.edu.ph, apbonto@ust.edu.ph)

Received: 5 July 2020, Revised: 24 June 2021, Accepted: 29 June 2021

\begin{abstract}
In this study, for the first time, hydrothermal treatment of Eleusine indica leaf extract and silver nitrate produced nanosilver immobilized in hydrothermal carbon synthesized at different reaction times (RT) - 6, 12, 24 and 48 h. The surface morphology of nanosilver hydrochar (AgNP@hydrochar) composites was studied using SEM, while their chemical functionalities were investigated using FT-IR, UV-Vis, XRF and EDX spectroscopy. The AgNP@hydrochar were observed to be agglomerated spherical particles with size ranges from 128 to $171 \mathrm{~nm}$. Varying $\mathrm{C}=\mathrm{O}$ and $\mathrm{C}=\mathrm{C}$ IR absorption peaks at different RT suggested that the plant extract reduced $\mathrm{Ag}^{+}$into $\mathrm{Ag}^{0}$ in solution. Elemental analysis using EDX showed that $\mathrm{Ag}$ is dominant in the composite (84.07\%) supported by the $\mathrm{Ag}$ spatial distribution as demonstrated by the EDX elemental mapping.
\end{abstract}

Keywords: Hydrothermal treatment, Silver Nanoparticle, Hydrochar, Eleusine indica

\section{Introduction}

As one of the most commonly synthesized nanomaterials, silver nanoparticles (AgNPs) are used in a wide range of applications such as antimicrobial properties [1,2], anticancer effects [3,4], antimalarial properties [5], dental agent [6], and sensing and imaging [7,8]. Therefore, both physical and chemical pathways have been developed for producing AgNPs. These synthetic procedures include evaporationcondensation, laser ablation, chemical reduction, microemulsion techniques, microwave-assisted synthesis, and green synthesis [9]. Many AgNPs have been produced using green synthesis because of their secure, reliable, and environmental-friendly approach. Furthermore, extracts from biological organisms (plant, bacteria, and fungi) are used as reducing agents in synthesizing AgNP [10,11]. Moreover, another advantage of green synthesis is the production of eco-friendly AgNPs [12].

Hydrothermal carbonization is a green, versatile process in producing sustainable carbon materials known as hydrothermal carbon or hydrochar $[13,14]$. This technique has been used to synthesize AgNPs and AgNP carbon micro/nanocomposites. Sun and Li [15] reported tunable-sized AgNP encapsulated in a carbonaceous shell produced through hydrothermal carbonization of glucose. While poly(N-vinyl-2pyrrolidone) as a reducing agent and carbon precursor produced polyhedral AgNPs via the hydrothermal route [16]. Combining both hydrothermal carbonization and green synthesis using biological extract is a good avenue in developing nano/microparticles with exciting properties. Plant extracts can act as a reducing agent and carbon source in producing AgNP - carbon nano/micro composites. Reports show that green hydrothermal synthesis of AgNPs is produced using plant extracts from gambier leaf [17], red cabbage [18], Pelargonium/Geranium leaf [19], tobacco stem [20], aloe vera [21,22] and blushwood berry [23] and bacterial extract from Streptomyces sp. GUT 21 [24]. Moreover, the employment of the hydrothermal method accelerates the activity of plant-based reducing agents in the production of AgNPs and $\mathrm{Au}-\mathrm{Ag}$ nanocomposites [25].

Eleusine indica, also known as wiregrass and goosegrass, is an endemic invasive grass in tropics and subtropical regions. The decoctions of the boiled plant are used as a traditional remedy for treating 
anti-helminthic, diuretic, diaphoretic and febrifuge problems [26]. The hexane extract from Eleusine indica shows remarkable activity towards methicillin-resistant Staphylococcus aureus and Pseudomonas aeruginosa, while the methanolic extract shows free-radical good scavenging activity using DPPH assay [27]. The plant extract also exhibits anthelmintic activity against Strongyloides stercoralis [28]. Cytotoxicity against Vero cells and antiviral activity towards Herpes Simplex Virus type 1 were reported elsewhere [29]. Besides, in vivo studies shows that decoction of Eleusine indica has a protective effect against $\mathrm{CCl}_{4}$ - induced hepatic oxidative damage in rats [26] and also inhibits the inflammation of the lipopolysaccharide-induced mouse lung [30]. These bioactive attributes of Eleusine indica are associated with the presence of secondary metabolites, including flavonoids, phenols, phenolic glycosides, saponins, cyanogenic glycosides, unsaturated lactones and glucosinolates [26]. In addition, metabolites such as sterol glucosides [31] and C-glycosylflavones [30] were isolated.

From a material science perspective, Syafiuddin et al. [32] firstly use the Eleusine indica as a reductant in reducing $\mathrm{Ag}^{+}$ions to form AgNPs. Moreover, using Eleusine indica shows the highest synthesis efficiency in producing AgNPs compare to other weed extracts. While, to the best of our knowledge, there is no report on the production of AgNP carbon composite using wiregrass extract as the bioreductant and carbon precursor via green hydrothermal synthesis. Moreover, these nanoparticles hydrochar composites may be utilized as functional materials for environmental remediation and antibacterial applications [33-35]. Herein, in this study, a facile 1-pot hydrothermal carbonization of aqueous Eleusine indica leaf extract and silver precursor was utilized in fabricating AgNPs immobilized on hydrochar.

\section{Materials and methods}

\section{Preparation of the aqueous Eleusine indica leaf extract}

Fresh leaves of Eleusine indica were collected from Bacoor City, Cavite. First, the leaves were washed thoroughly 3 times with tap water and distilled water to remove any impurities. Then, the samples were then air-dried for several days to minimize moisture content. The resulting dried leaves were powdered using a coffee grinder, then sieved using a 100-mesh sieve. Finally, 5.0 g of the powdered leaves were boiled for $1 \mathrm{~h}$ in $100 \mathrm{~mL}$ distilled water and filtered through Whatman no. 1 filter paper. The filtered extract was stored in the refrigerator at $4{ }^{\circ} \mathrm{C}$ until further use. This aqueous extract was used as the reductant for $\mathrm{Ag}^{+}$in the $\mathrm{AgNP}$ synthesis.

\section{Synthesis of AgNP@hydrochar composite}

For the hydrothermal synthesis, $15 \mathrm{~mL}$ of the plant extract was added to $15 \mathrm{~mL}$ of $10 \mathrm{mM}$ silver nitrate. The mixture was enclosed in a hydrothermal reactor, incubated at $180{ }^{\circ} \mathrm{C}$, and observed through different reaction times of $6,12,24$ and $48 \mathrm{~h}$. The change in color from light yellow to black solution was observed, indicating the carbonization of plant extract and the formation of silver nanoparticles (Figure 1). Then, the mixture was filtered to obtain the AgNP@hydrochar composite. The formation of black carbon material was attributed to the hydrothermal carbonization (HTC) of carbon precursors, which in this study were the phytochemicals present in the aqueous extract. Moreover, these carbon precursors may act as reducing agents and stabilizers in AgNP synthesis [36]. Several studies reported similar observations in synthesizing AgNP under hydrothermal treatment using tobacco stem [20], Pelargonium/Geranium leaf extract [19] and aloe vera leaf extract [21,22,37]

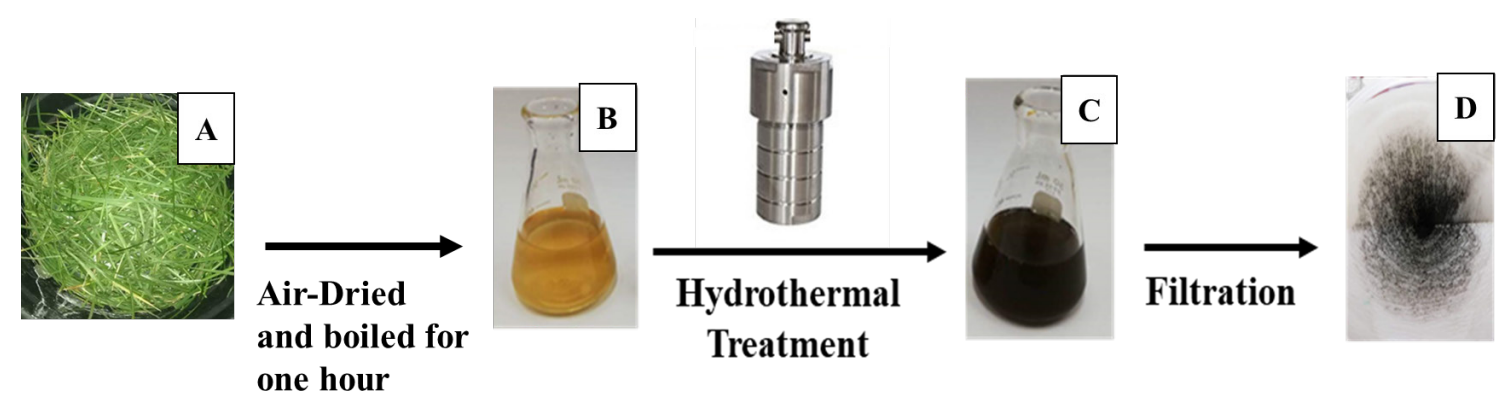

Figure 1 The raw sample A), the hydrothermal carbonization (before B) and after C)) of Eleusine indica aqueous extract, C) AgNP@hydrochar composite suspension and D) residues left after filtration. 


\section{Morphological and elemental composition of AgNP@hydrochar composite}

The morphology of hydrothermally synthesized nanosilver composite in different reaction times was observed using scanning electron microscopy (JSM, 5310, JEOL SEM) at $20 \mathrm{kV}$. Samples were manually snapped, mounted on aluminum studs using carbon tape, and sputter-coated with gold. Magnifications of $10,000 \times$ and 35,000 $\times$ were obtained to observe the shape and size of the synthesized composites. The average size of the composites was measured using ImageJ software. Energy dispersive X-ray spectroscopy (EDX) analysis (Phenom XL 2015 LR1) was performed to determine and map the elemental composition of synthesized composite.

\section{Spatial distribution elemental components of AgNP@hydrochar composite}

The formation of AgNPs was monitored at regular intervals by scanning the reacting mixture under the spectrophotometer due to their surface plasmon resonance (SPR). The absorption spectra of the solutions were taken using a UV-Vis spectrophotometer (Hitachi U-2900) in a 1-cm optical path quartz cuvette. Fourier transform infrared spectroscopy (FT-IR) Analysis (Nicolet 6700) was used to determine the functional groups of synthesized AgNP@hydrochar composite. The samples were prepared in $\mathrm{KBr}$ power (1:10) and recorded in the $4000-400 \mathrm{~cm}^{-1}$ region.

\section{Results and discussion}

Morphological features using scanning electron microscopy

The surface morphology of synthesized AgNP@hydrochars was imaged using scanning electron microscopy, as shown in Figure 2. All products exhibited similar structures having highly agglomerated particles with spherical shapes (less than 1 micron) and non-spherical irregular shapes (more than 1 micron). Ten AgNP@hydrochar particles were measured by ImageJ software, giving approximate particle sizes of $169.32 \pm 55.94,128.37 \pm 15.65,162.50 \pm 42.90$ and $171.87 \pm 36.65 \mathrm{~nm}$ for $6,12,24$ and $48 \mathrm{~h}$ treatment, respectively (shown in Table 1). No significant change in particle diameter was observed in the sizes of AgNPs for different reaction times, indicating that the size of particles has no distinct trend in increasing reaction time. In comparison, other plant extracts produced similar spherical AgNPs (65 - 100 $\mathrm{nm}$ ) through hydrothermal treatment of aqueous red cabbage extract [18] and Pelargonium/Geranium leaf extract [19]. At the same time, another shape was also produced during green hydrothermal treatment, like oval-shaped AgNPs from Laminaria japonica extract [38].

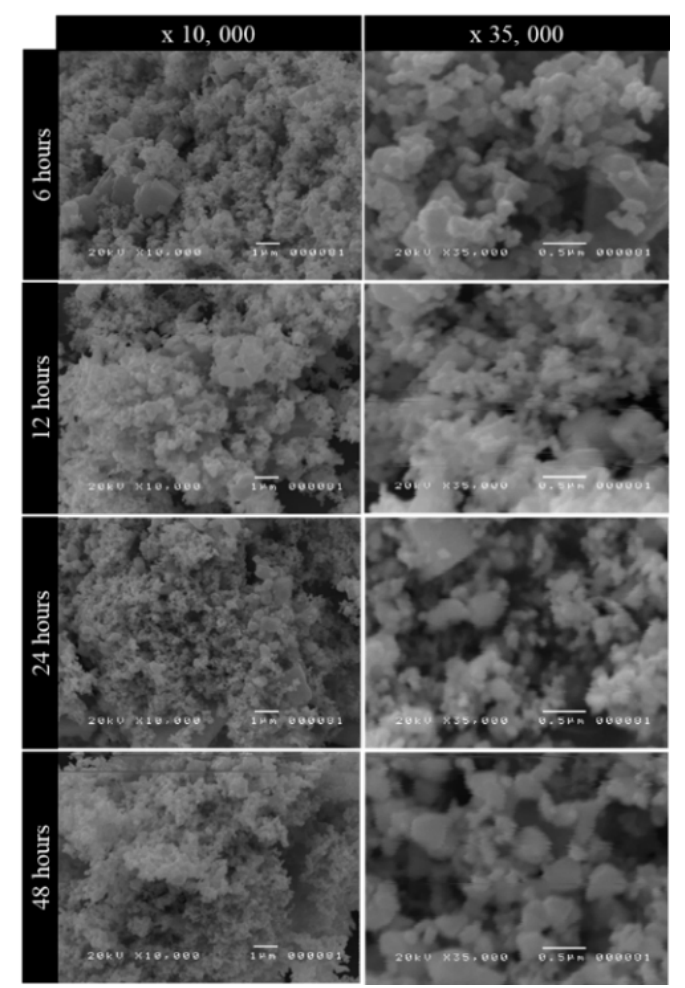

Figure 2 SEM images of AgNP@hydrochar composites at 6, 12, 24 and 48 h hydrothermal treatment. 
Table 1 Size of AgNP@hydrochar composites.

\begin{tabular}{cc}
\hline Reaction Time (h) & Size (nm) \\
\hline 6 & $169.32 \pm 55.94^{\mathrm{a}}$ \\
12 & $128.37 \pm 15.65^{\mathrm{a}}$ \\
24 & $162.50 \pm 42.90^{\mathrm{a}}$ \\
48 & $171.87 \pm 36.65^{\mathrm{a}}$ \\
\hline
\end{tabular}

Mean \pm SD: Values with a different letter in the same column are significantly different $(p<0.05)$.

\section{FTIR analysis}

Surface functional group changes in the AgNP@hydrochar at increasing hydrothermal reaction time were studied using FT-IR spectroscopy. Figure $\mathbf{3}$ compares the FTIR spectra of synthesized AgNP@hydrochar at different reaction times of 6, 12, 24 and 48 h. Furthermore, all hydrochar products at different reaction times have similar characteristic peaks of the hydroxyl group (O-H stretching), carbonyl $\left(\mathrm{C}=\mathrm{O}\right.$, stretching) and aromatic $(\mathrm{C}=\mathrm{C}$ stretching $)$. The $\mathrm{O}-\mathrm{H}$ peak was observed around $3430 \mathrm{~cm}^{-1}$ having a broad absorption band corresponding to stretching vibration [20]. The peak at $1647 \mathrm{~cm}^{-1}$ was associated with the $\mathrm{C}=\mathrm{O}$ stretching vibration of the carboxylic group [39]. Peaks at 1566 [40], 1411 and $1384 \mathrm{~cm}^{-1}[20]$ could be attributed to the $\mathrm{C}=\mathrm{C}$ stretching of the aromatic group. These reported functional groups were associated with the present metabolites in the aqueous Eleusine indica extract. Qualitative analysis of methanolic Eleusine indica extract showed alkaloids, steroids, flavonoids, tannins and glycosides [41]. Besides, sterol glucosides [31] and C-glycosylflavone [30] were isolated. The -OH and $\mathrm{C}=\mathrm{O}$ groups present in these phytochemicals were involved in reducing $\mathrm{Ag}^{+}$and the formation of $\mathrm{AgNPs}$ during HT. In comparison, the aromatic peaks were innately present and produced during hydrothermal carbonization of phytochemicals present in the aqueous Eleusine indica extract. The decrease in the intensity bands at 3430 and $1647 \mathrm{~cm}^{-1}$ upon increasing $\mathrm{HTC}$ time suggests that the $\mathrm{C}-\mathrm{O}$ and $\mathrm{C}=\mathrm{O}$ functional groups reduced $\mathrm{Ag}^{+}$. In a related study by Li et al. [39] and Liang et al. [20] on hydrothermal carbonization of Arabic gum and tobacco stem, respectively, these relative decrease in IR absorption of $\mathrm{C}-\mathrm{O}$ and $\mathrm{C}=\mathrm{O}$ indicates agglomeration because of AgNP binds on these functional groups, essentially decreasing the IR absorption of $\mathrm{C}-\mathrm{O}$ and $\mathrm{C}=\mathrm{O}$ overall.

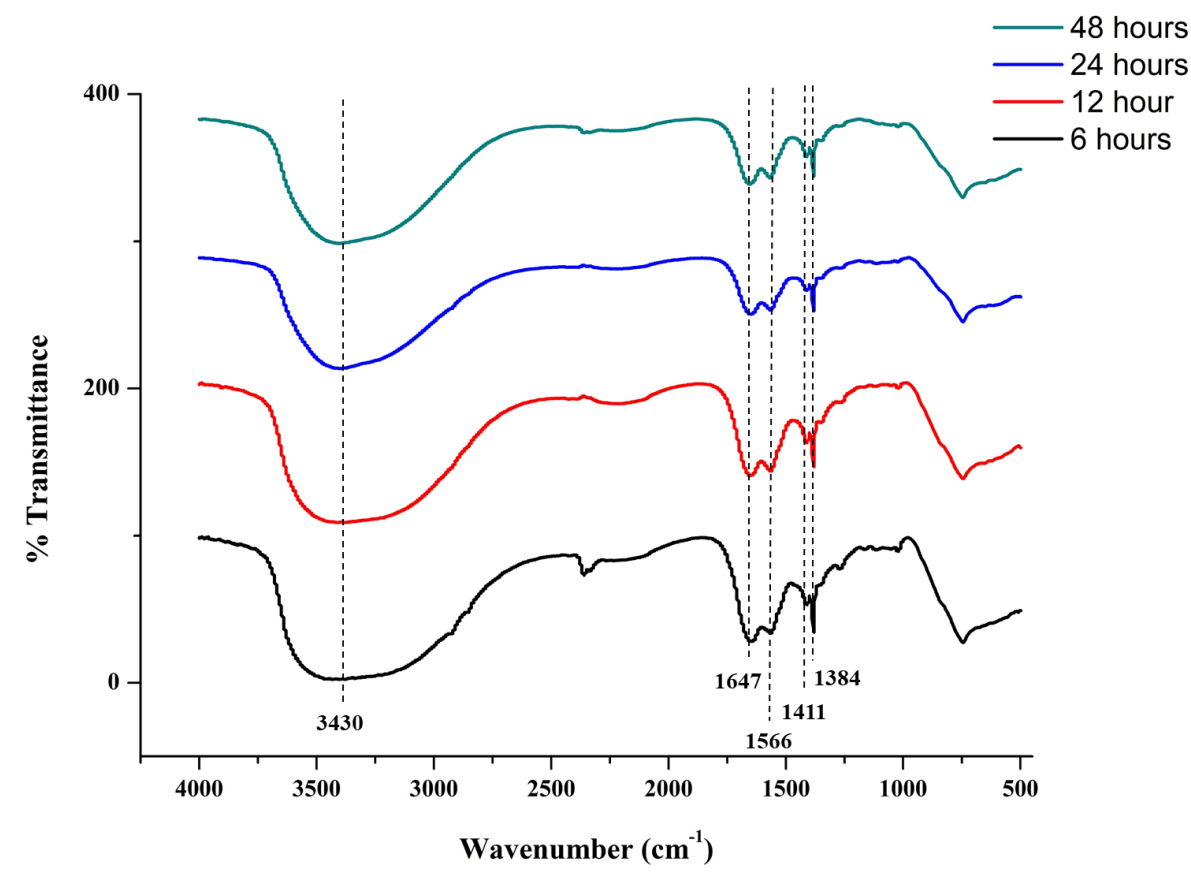

Figure 3 FT-IR spectra of synthesized AgNP@hydrochar composites in increasing reaction time 


\section{UV-Vis analysis}

Figure 4 shows the overlaid UV-Vis scan of AgNP@hydrochar solutions treated at different reaction times. AgNPs are generally known to display a UV-Visible absorption maximum ranging from 400 to $500 \mathrm{~nm}$ due to their surface plasmon resonance [42]. However, no peaks were detected in these UV-Vis ranges for the synthesized AgNP@hydrochar. This attenuation of surface plasmon resonance is due to the low concentration of $\mathrm{Ag}$ nanoparticles suspended in the solution, suggesting that most $\mathrm{Ag}$ nanoparticles were bound to the heavier hydrochar residues [43]. This observation was supported by black precipitate (Figure 1C) in the solution after filtration.

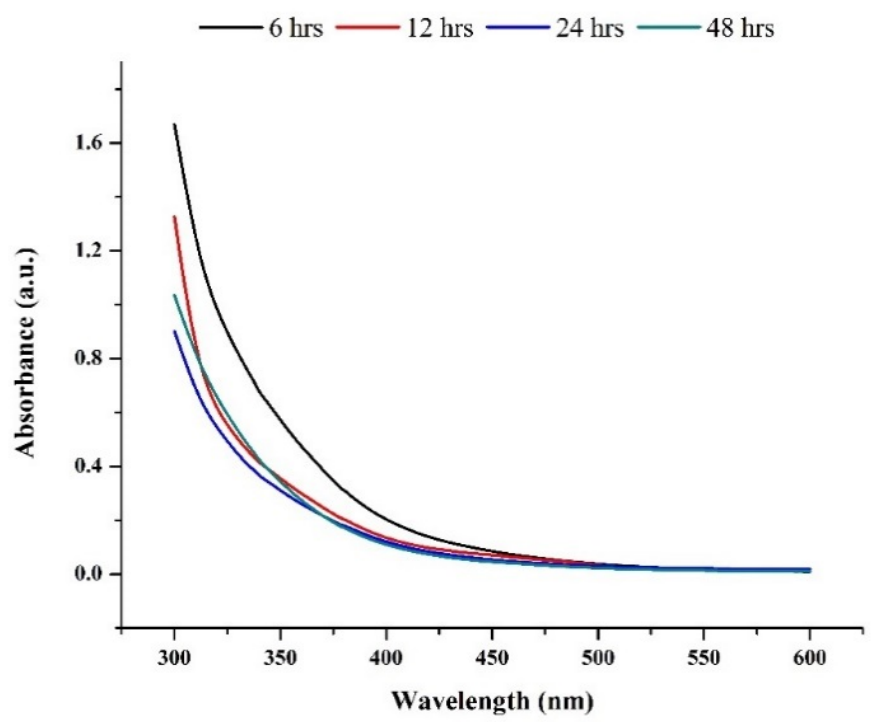

Figure 4 UV-Vis Spectra of nanosilver hydrochar composites obtained at different synthesis times.

\section{Elemental compositions using X-ray Fluorescence Spectroscopy}

Energy-dispersive X-ray spectroscopy (EDX) analysis was done to determine the elemental composition and relative amounts of AgNP@hydrochar synthesized after $48 \mathrm{~h}$ (shown in Figure 5). Silver $(\mathrm{Ag})$ was the most abundant element $(84.07 \%)$ in the structure. Major emission energy identification peaks for silver displayed to correspond with peaks in the spectrum at approximately $3 \mathrm{keV}$, thus attesting that silver has been correctly identified in AgNPs. While carbon (C) and oxygen (O) were detected in AgNP@hydrochar, accounting for 6.22 and $4.03 \%$, respectively. The $\mathrm{C}$ and $\mathrm{O}$ were attributed to the plant metabolites present in the extract and supported with the C-O functional groups found in the FTIR spectra. While the other elements such as $\mathrm{Cl}$ and $\mathrm{K}$ found in the EDX analysis were associated with the metals or ions innately present in the plant extract before the AgNP synthesis. The distribution of elements in the nanostructure was mapped using the SEM-EDX technique shown in Figure 6. Ag distribution further confirmed that AgNPs were evenly dispersed in the material. Like Ag, $\mathrm{C}$ and $\mathrm{O}$ were also evenly distributed on the AgNPs. 


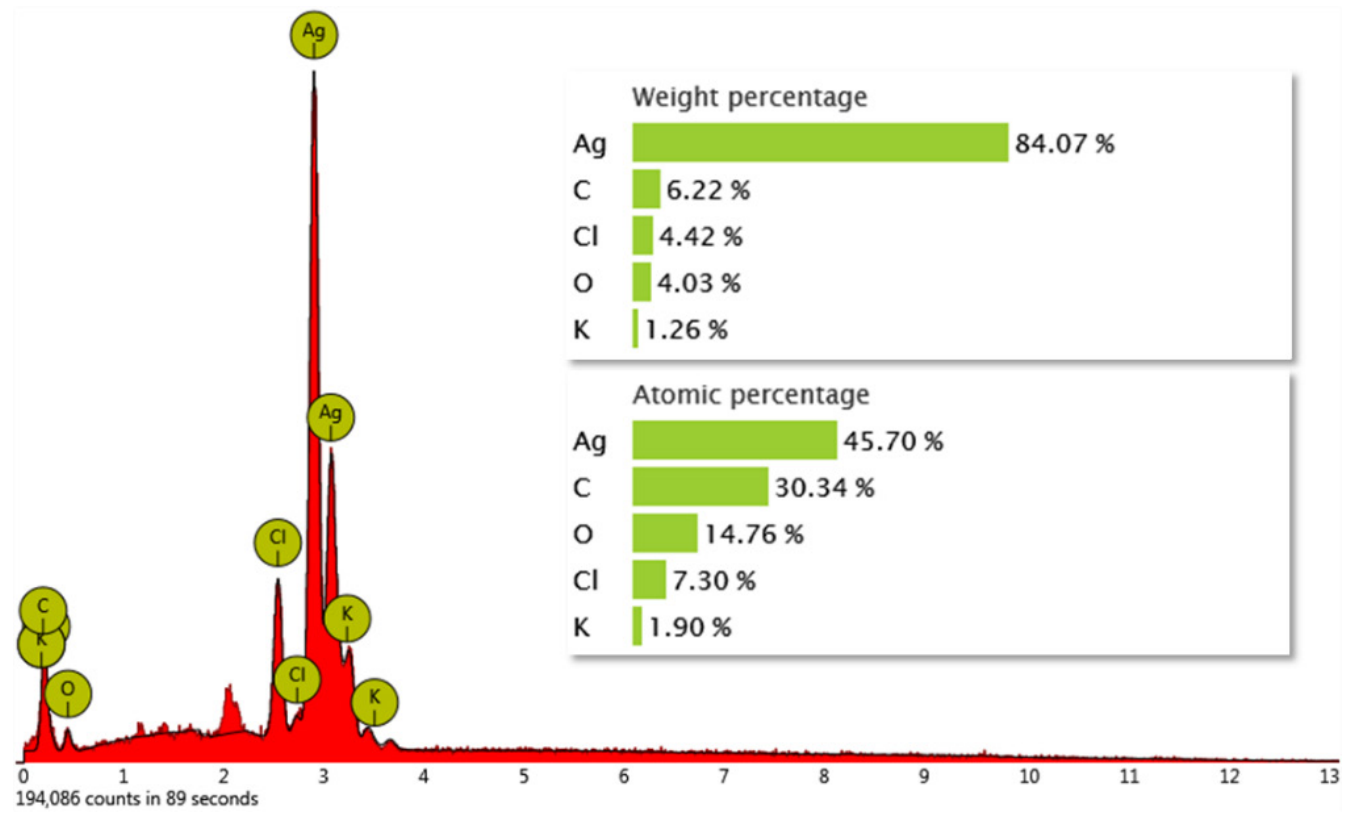

Figure 5 EDX spectrum of nanosilver hydrochar composite and its elemental composition

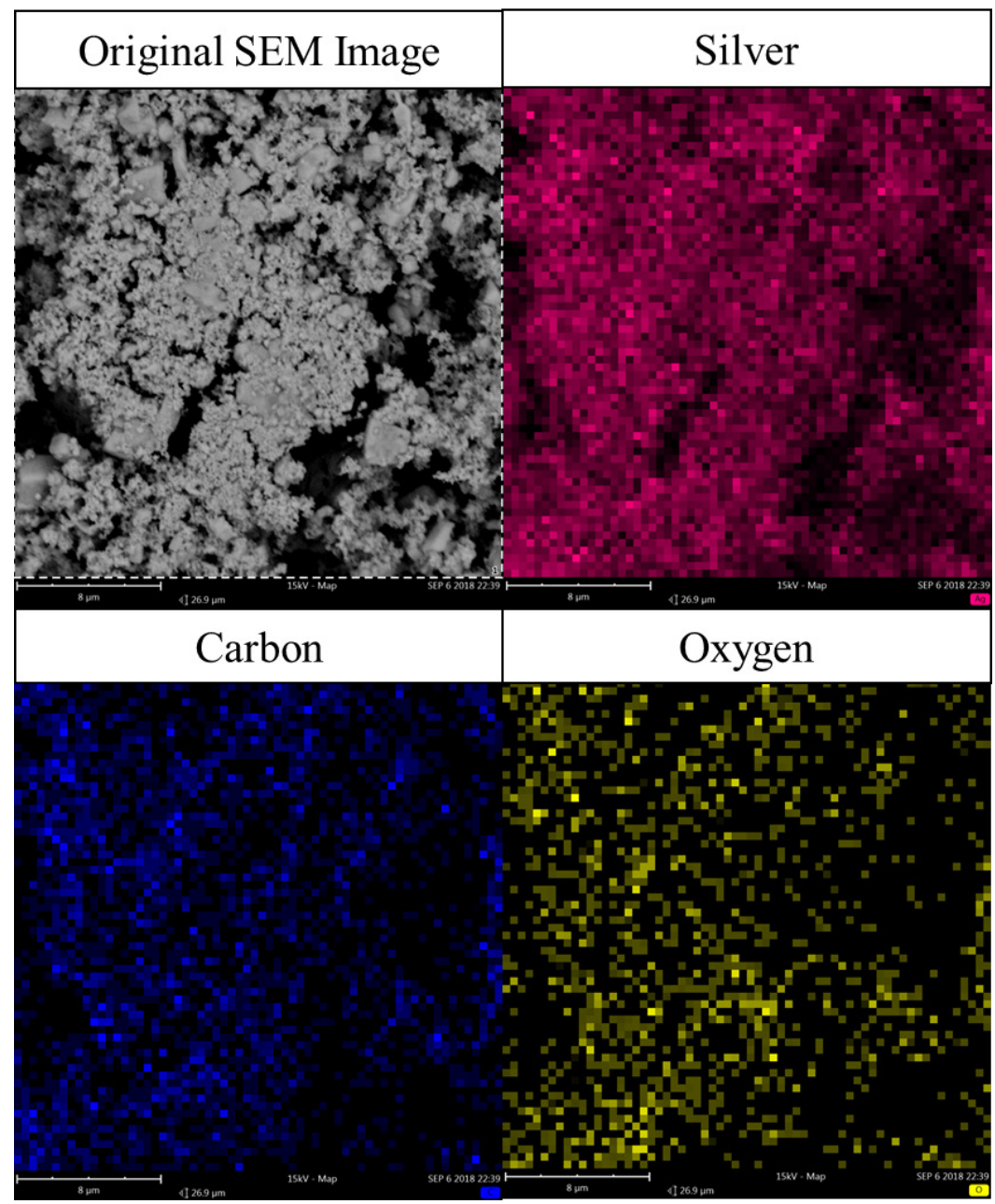

Figure 6 Silver, Carbon and Oxygen Distribution of AgNP@hydrochar composite. 


\section{Conclusions}

AgNP@hydrochar composites were successfully synthesized using an aqueous extract of Eleusine indica leaves through the hydrothermal route for the first time. Characterization of the composite showed spherical shapes with $128-171 \mathrm{~nm}$ as measured in SEM images. AgNP@hydrochar has functional groups of carbonyl $(\mathrm{C}=\mathrm{O})$ and aromatic $(\mathrm{C}=\mathrm{C})$ peak, indicating the plant extract's hydrothermal carbonization. The decrease in intensity bands at 3430 and $1647 \mathrm{~cm}^{-1}$ and absence of absorption band indicate the aggregation of AgNP@hydrochar. Moreover, Ag is the most abundant and well distributed in AgNP@hydrochar, as shown in the EDX results. This synthesized composite may be utilized as functional materials for future applications such as environmental remediation and antibacterial applications.

\section{Acknowledgments}

A P. Bonto and C. M. H. Ebreo would like to acknowledge the Department of Science and Technology- Science Education Institute (DOST-SEI) through the Accelerated Science and Technology Human Resource Development (ASTHRDP) program the graduate scholarship.

\section{References}

[1] S Rajeshkumar and LV Bharath. Mechanism of plant-mediated synthesis of silver nanoparticles - A review on biomolecules involved, characterisation and antibacterial activity. Chem. Biol. Interact. 2017; 273, 219-27.

[2] JPO Bantang, UG Bigol and DH Camacho. Gel and film composites of silver nanoparticles in $\kappa-$, t-, and $\lambda$-Carrageenans: One-pot synthesis, characterization, and bioactivities. BioNanoScience 2021; 11, 53-66.

[3] KBR Ahmed, AM Nagy, RP Brown, Q Zhang, SG Malghan and PL Goering. Silver nanoparticles: Significance of physicochemical properties and assay interference on the interpretation of in vitro cytotoxicity studies. Toxicol. Vitro. 2017; 38, 179-92.

[4] MN Owaid, GA Naeem, RF Muslim and RS Oleiwi. Synthesis, characterization and antitumor efficacy of silver nanoparticle from agaricus bisporus pileus, basidiomycota. Walailak J. Sci. Tech. 2020; 17, 75-87.

[5] M Rai, AP Ingle, P Paralikar, I Gupta, S Medici and CA Santos. Recent advances in use of silver nanoparticles as antimalarial agents. Int. J. Pharm. 2017; 526, 254-70.

[6] RA Bapat, TV Chaubal, CP Joshi, PR Bapat, H Choudhury, M Pandey, B Gorain and P Kesharwani. An overview of application of silver nanoparticles for biomaterials in dentistry. Mater. Sci. Eng. C 2018; 91, 881-98.

[7] C Caro, PM Castillo, R Klippstein, D Pozo and AP Zaderenko. Silver nanoparticles: Sensing and imaging applications. In: D Pozo (Ed.). Silver nanoparticles. $11^{\text {th }}$ ed. IntechOpen, 2010, p. 201-25.

[8] MOS Lobregas, JPO Bantang and DH Camacho. Carrageenan-stabilized silver nanoparticle gel probe kit for colorimetric sensing of mercury (II) using digital image analysis. Sens. Bio-Sensing Res. 2019; 26, 100303.

[9] HD Beyene, AA Werkneh, HK Bezabh and TG Ambaye. Synthesis paradigm and applications of silver nanoparticles (AgNPs), a review. Sustain. Mater. Tech. 2017; 13, 18-23.

[10] M Mohammadlou, H Maghsoudi and H Jafarizadeh-Malmiri. A review on green silver nanoparticles based on plants: Synthesis, potential applications and eco-friendly approach. Int. Food Res. J. 2016; 23, 446-63.

[11] H Chandra, P Kumari, E Bontempi and S Yadav. Medicinal plants: Treasure trove for green synthesis of metallic nanoparticles and their biomedical applications. Biocatal. Agr. Biotechnol. 2020; 24, 101518.

[12] N Roy, A Gaur, A Jain, S Bhattacharya and V Rani. Green synthesis of silver nanoparticles: An approach to overcome toxicity. Environ. Toxicol. Pharmacol. 2013; 36, 807-12.

[13] M Sevilla and MM Titirici. Hydrothermal carbonization: A greener route towards the synthesis of advanced carbon materials. Boletín del Grupo Español del Carbón 2012; 25, 7-17.

[14] M Titirici and M Antonietti. Chemistry and materials options of sustainable carbon materials made by hydrothermal carbonization. Chem. Soc. Rev. 2010; 39, 103-16.

[15] X Sun and Y Li. Ag@C core/shell structured nanoparticles: Controlled synthesis, characterization, and assembly. Langmuir 2005; 21, 6019-24.

[16] J Zou, Y Xu, B Hou, D Wu and Y Sun. Controlled growth of silver nanoparticles in a hydrothermal process. China Particuology 2007; 5, 206-12. 
[17] S Arief, V Gustia, D Vanda, T Ban and Y Ohya. Hydrothermal synthesized Ag nanoparticles using bioreductor of gambier leaf extract (Uncaria gambier Roxb ). J. Chem. Pharm. Res. 2015; 7, 189-92.

[18] I Ocsoy, A Demirbas, ES Mclamore, B Altinsoy, N Ildiz and A Baldemir. Green synthesis with incorporated hydrothermal approaches for silver nanoparticles formation and enhanced antimicrobial activity against bacterial and fungal pathogens. J. Mol. Liq. 2017; 238, 263-9.

[19] M Mohammadlou, H Jafarizadeh-malmiri and H Maghsoudi. Hydrothermal green synthesis of silver nanoparticles using Pelargonium/Geranium leaf extract and evaluation of their antifungal activity. Green Proc. Synth. 2017; 6, 31-42.

[20] M Liang, X Liu, L Wang, Y He, F Huang, B Li, K Zhang and H Tian. Preparation and characterization of nano silver immobilized hydrochar derived from hydrothermal carbonization of tobacco stem. Mater. Res. Express 2020; 7, 015611.

[21] D Hariharan, P Thangamuniyandi, AJ Christy, R Vasantharaja, P Selvakumar, S Sagadevan, A Pugazhendhi and L Nehru. Enhanced photocatalysis and anticancer activity of green hydrothermal synthesized Ag@TiO2 nanoparticles. J. Photochem. Photobiol. B Biol. 2020; 202, 111636.

[22] P Tippayawat, N Phromviyo, P Boueroy and A Chompoosor. Green synthesis of silver nanoparticles in aloe vera plant extract prepared by a hydrothermal method and their synergistic antibacterial activity. PeerJ 2006; 4, e2589.

[23] SP Vinay, Udayabhanu, G Nagaraju, CP Chandrappa and N Chandrasekha. A novel, green, rapid, nonchemical route hydrothermal assisted biosynthesis of Ag nanomaterial by blushwood berry extract and evaluation of its diverse applications. Appl. Nanosci. 2020; 10, 3341-51.

[24] PP Desai, C Prabhurajeshwar and K Chandrakanth. Hydrothermal assisted biosynthesis of silver nanoparticles from Streptomyces sp. GUT 21 (KU500633) and its therapeutic antimicrobial activity, J. Nanostruct. Chem. 2016; 6, 235-46.

[25] A Pani, JH Lee and SII Yun. Autoclave mediated one-pot-one-minute synthesis of AgNPs and AuAg nanocomposite from Melia azedarach bark extract with antimicrobial activity against food pathogens. Chem. Cent. J. 2016; 10, 15.

[26] M Iqbal and C Gnanaraj. Eleusine indica L. possesses antioxidant activity and precludes carbon tetrachloride (CC14)-mediated oxidative hepatic damage in rats. Environ. Health Prev. Med. 2012; $17,307-15$.

[27] AS Al-zubairi, AB Abdul, SI Abdelwahab, CY Peng, S Mohan and MM Elhassan. Eleucine indica possesses antioxidant, antibacterial and cytotoxic properties, evidence-based complement. Altern. Med. 2011; 2011, 965370.

[28] F Morah and M Otuk. Antimicrobial and anthelmintic activity of Eleusine indica. Acta Sci. Intellectus 2015; 1, 28-32.

[29] R Iberahim, WA Yaacob and N Ibrahim. Phytochemistry cytotoxicity and antiviral activity of Eleusine indica (sambau). AIP Conf. Proc. 2015; 1678, 030013.

[30] GOD Melo, MF Muzitano, A Legora-machado, TA Almeida, DBD Oliveira, CR Kaiser, VLG Koatz and SS Costa. C-Glycosylflavones from the aerial parts of Eleusine indica inhibit LPS induced mouse lung inflammation. Planta Med. 2004; 71, 362-3.

[31] N Phuong, T Sung, H Ripperger and G Adam. Sterol glucosides from Eleucine indica. Planta Med. 1994; 60, 498.

[32] A Syafiuddin, Salmiati, T Hadibarata, ABH Kueh and MR Salim. Novel weed-extracted silver nanoparticles and their antibacterial appraisal against a rare bacterium from river and sewage treatment plan. Nanomaterials 2018; 8,9 .

[33] MR Louis, LG Sorokhaibam, SK Chaudhary and S Bundale. Silver-loaded biomass (Delonix regia) with antibacterial properties as porous carbon composite towards comprehensive water purification, Int. J. Environ. Sci. Tech. 2020; 17, 2415-32.

[34] C Gai, F Zhang, Q Lang, T Liu, N Peng, Z Liu. Facile one-pot synthesis of iron nanoparticles immobilized into the porous hydrochar for catalytic decomposition of phenol. Appl. Catal. B Environ. 2017; 204, 566-76.

[35] Y Zhang, Q Jiang, S Jiang, H Li, R Zhang, J Qu, S Zhang and W Han. One-step synthesis of biochar supported nZVI composites for highly efficient activating persulfate to oxidatively degrade atrazine. Chem. Eng. J. 2021; 420, 129868.

[36] H Simsir, N Eltugral and S Karagoz. The role of capping agents in the fabrication of nano-silverdecorated hydrothermal carbons. J. Environ. Chem. Eng. 2019; 7, 103415.

[37] O Ahmadi, H Jafarizadeh-malmiri and N Jodeiri. Optimization of processing parameters for hydrothermal silver nanoparticles synthesis using aloe vera leaf extract and estimation of their physico-chemical and antifungal properties. Zeitschrift für Physikalische Chemie 2018; 233, 651-67. 
[38] D Kim, R Ganesh, S Shinde, A Syed, F Ameen and G Ghodake. Green synthesis of silver nanoparticles using Laminaria japonica extract: Characterization and seedling growth assessment. J. Clean. Prod. 2018; 172, 2910-8.

[39] Y Li, W Gan, J Zhou, Z Lu, C Yang and T Ge. Hydrothermal synthesis of silver nanoparticles in Arabic gum aqueous solutions. Trans. Nonferrous Met. Soc. China 2015; 25, 2081-6.

[40] W Maulina, R Kusumaningtyas, Z Rachmawati, S Arkundato, L Rohman and E Purwandari. Carbonization process of water hyacinth as an alternative renewable energy material for biomass cook stoves applications. IOP Conf. Ser. Earth Environ. Sci. 2019; 239, 012035.

[41] TD Balangcod, VL Vallejo, M Patacsil, O Apostol, L Marie, VA Laruan, J Manuel, S Cortez and RM Gutierrez. Phytochemical screening and antibacterial activity of selected medicinal plants of Bayabas, Sablan, Benguet Province, Cordillera Administrative Region, Luzon, Philippines. Indian J. Tradit. Knowl. 2012; 11, 580-5.

[42] M Sastry, KS Mayya and K Bandyopadhyay. $\mathrm{pH}$ dependent changes in the optical properties of carboxylic acid derivatized silver colloidal particles. Colloid. Surface. Physicochem. Eng. Aspect. 1997; 127, 221-8.

[43] DV Quang and NH Chau. The effect of hydrothermal treatment on silver nanoparticles stabilized by chitosan and its possible application to produce mesoporous silver powder. J. Powder Tech. 2013; 2013, 281639. 